\title{
Brain Plasticity and Intellectual Ability Are Influenced by Shared Genes
}

\author{
Rachel G. H. Brans, ${ }^{1}$ René S. Kahn, ${ }^{1}$ Hugo G. Schnack, ${ }^{1}$ G. Caroline M. van Baal, ${ }^{1}$ Danielle Posthuma, ${ }^{2}$ \\ Neeltje E. M. van Haren, ${ }^{1}$ Claude Lepage, ${ }^{3}$ Jason P. Lerch, ${ }^{3}$ D. Louis Collins, ${ }^{3}$ Alan C. Evans, ${ }^{3}$ Dorret I. Boomsma, ${ }^{2}$ \\ and Hilleke E. Hulshoff Pol ${ }^{1}$ \\ ${ }^{1}$ Rudolf Magnus Institute for Neuroscience, Department of Psychiatry, University Medical Centre Utrecht, 3584 CX Utrecht, The Netherlands, ${ }^{2}$ Department \\ of Biological Psychology, Free University Amsterdam, 1081 BT Amsterdam, The Netherlands, and ${ }^{3}$ McConnell Brain Imaging Centre, Montreal Neurological \\ Institute, McGill University, Montreal, Quebec H3A 2B4, Canada
}

\begin{abstract}
Although the adult brain is considered to be fully developed and stable until senescence when its size steadily decreases, such stability seems at odds with continued human (intellectual) development throughout life. Moreover, although variation in human brain size is highly heritable, we do not know the extent to which genes contribute to individual differences in brain plasticity. In this longitudinal magnetic resonance imaging study in twins, we report considerable thinning of the frontal cortex and thickening of the medial temporal cortex with increasing age and find this change to be heritable and partly related to cognitive ability. Specifically, adults with higher intelligence show attenuated cortical thinning and more pronounced cortical thickening over time than do subjects with average or below average IQ. Genes influencing variability in both intelligence and brain plasticity partly drive these associations. Thus, not only does the brain continue to change well into adulthood, these changes are functionally relevant because they are related to intelligence.
\end{abstract}

\section{Introduction}

As was already postulated in 1892 by Ramõn y Cajal (1892), the human brain changes throughout life. It reaches $\approx 90 \%$ of its adult size around the age of six years (Giedd et al., 1999), but changes in the brain continue to take place in children and adolescents (Giedd et al., 1999; Gogtay et al., 2004); while in senescence, a consistent loss of brain tissue is found (Liu et al., 2003; Raz et al., 2005; Resnick et al., 2003; Kramer et al., 2007). Despite these marked changes over time at both extremes of the age range, brain size has often been considered to be static during the largest period of our lives. Interestingly, this belief is mostly based on cross-sectional data. However, a static brain seems to be at odds with our continued (intellectual) development after adolescence. In fact it is hard to envision meeting these (intellectual and social) challenges with a brain incapable of changing and adapting to the environment.

We therefore hypothesized that (1) structural changes occur in the adult brain; (2) these changes are related to intelligence (as has previously been reported to be the case in childhood [Shaw et al., 2006]), and (3) because both cortical thickness (Thompson et al., 2001) and intelligence (Plomin and Spinath, 2004) are heritable

Received Nov. 24, 2009; revised Jan. 24, 2010; accepted Feb. 8, 2010.

This work was funded by Netherlands Organisation for Scientific Research (NWO) Grant no. 908-02-123 (to H.H.), NW0 VIDI Grant 917-46-370 (to H.H.), NW0/Spinoza Prize Grant 56-464-14192 (to D.B.), and NWO VIDI Grant 016-065-318 (to D.P.) from the Netherlands Organization for Health Research and Development (ZonMw). We thank Martijn van den Heuvel and René Mandl for their contribution to the cortical thickness procedures and Jackie Senior for editing the final text.

Correspondence should be addressed to Hilleke E. Hulshoff Pol, Rudolf Magnus Institute for Neuroscience, Department of Psychiatry, University Medical Centre Utrecht, A01.126, Heidelberglaan 100, 3584 CX Utrecht, The Netherlands. E-mail: H.E.Hulshoff@umcutrecht.nl.

DOI:10.1523/JNEUROSCI.5841-09.2010

Copyright $\odot 2010$ the authors $\quad 0270-6474 / 10 / 305519-06 \$ 15.00 / 0$ traits and brain structure is positively associated with intelligence through shared genes (Thompson et al., 2001; Posthuma et al., 2002; Toga and Thompson, 2005; Hulshoff Pol and Kahn, 2008) changes in cortical thickness are driven by genes overlapping with those determining IQ. We applied the extended twin model to determine the relative contributions of genetic, common, and unique environmental influences on variation in cortical thickness change and their common origin with intelligence.

\section{Materials and Methods}

Subjects. Twins and their siblings were recruited from the twin-pair cohort at the University Medical Centre Utrecht (Baaré et al., 2001) and the Netherlands Twin Registry, Free University Amsterdam (Boomsma). Of the 242 participants from 106 twin families, 183 from 87 families completed the 5-year follow-up, including 52 monozygotic males, 31 dizygotic males, 25 monozygotic females, 29 dizygotic females, 24 dizygotic opposite sex twins (12 male and 12 female), and 22 siblings (11 male and 11 female). Mean age at baseline was 29.63 years (SD: 7.52). All participants gave written informed consent. DNA testing using the polymorphic markers D06S474, D07S1804, D07S1870, D12S811, D13S119, D13S126, D13S788, D20S119, D22S683, DXS1001, and ELN, or D13S317, VWA, D74520, D35158, TH01, TP0X, CSF1P0, and D55818 determined zygosity. Except for one twin pair, all twins and their siblings were reared together. Two twin pairs were born by caesarean section delivery. Mental and physical health was assessed at baseline and at follow-up by means of the Comprehensive Assessment of Symptoms and History (CASH; Andreasen et al., 1992), and by a medical history inventory, respectively. In addition, at baseline the Family Interview for Genetic Studies (FIGS; Maxwell, 1992) was completed. This study was approved by the medical ethics committee for research in humans (METC), University Medical Centre Utrecht, the Netherlands and was carried out according to the directives of the "Declaration of Helsinki" (Edinburgh amendment, 2000) (Table 1). 
Table 1. Demographics of monozygotic and dizygotic twin-pairs and their siblings*

\begin{tabular}{lccc}
\hline & $\mathrm{MZ}$ & $\mathrm{DZ}$ & Siblings \\
\hline$n$, male/female & $52 / 25$ & $43 / 41$ & $11 / 11$ \\
Age at time of the first scan, $\mathrm{y}$ & $31.1(8.9)$ & $28.7(6.7)$ & $28.0(3.1)$ \\
Height, $\mathrm{cm}$ & $177(8.9)$ & $177(8.2)$ & $175(12.5)$ \\
Handedness, r/l/ambidextrous & $60 / 15 / 2$ & $69 / 8 / 7$ & $17 / 4 / 1$ \\
Level of education, $y$ & $13.7(2.9)$ & $13.3(2.6)$ & $12.7(3.2)$ \\
Parental level of education, $y$ & $12.2(2.6)$ & $12.0(2.7)$ & $12.1(2.8)$ \\
Follow-up duration, $y$ & $5.1(0.56)$ & $5.5(0.70)$ & $5.4(0.55)$ \\
$\mathrm{IQ}^{\dagger}$ & $104.3(16.1)$ & $104.4(8.5)$ & $106.4(12.6)$ \\
\hline
\end{tabular}

*Values are total number of participants $(n)$, means, and standard deviations, unless otherwise indicated.

${ }^{\dagger}$ Available in $36 \mathrm{MZ}, 53 \mathrm{DZ}$, and 17 siblings.

Brain imaging. Magnetic resonance imaging brain scans were acquired on a Philips NT scanner (Best, the Netherlands) operating at $1.5 \mathrm{~T}$ in all subjects. T1-weighted three-dimensional fast field echo (3D-FFE) scans with 160 to 180 contiguous coronal slices scans (echo time $[\mathrm{TE}]=4.6 \mathrm{~ms}$, repetition time $[\mathrm{TR}]=30 \mathrm{~ms}$, flip angle $=30^{\circ}, 1 \times 1 \times 1.2 \mathrm{~mm}^{3}$ voxels), and T2-weighted dual-echo turbo-spin-echo (DE-TSE) scans with 120 contiguous coronal slices $(\mathrm{TE} 1=14 \mathrm{~ms}, \mathrm{TE} 2=80 \mathrm{~ms}$, TR $=6350 \mathrm{~ms}$, flip angle $=90^{\circ}, 1 \times 1 \times 1.6 \mathrm{~mm}^{3}$ voxels $)$ of the whole head were used for quantitative measurements. In addition, T2-weighted dual-echo turbospin-echo $($ DE-TSE $)$ scans $\left(\right.$ TE1 $=9 \mathrm{~ms}, \mathrm{TE} 2=100 \mathrm{~ms}$, flip angle $=90^{\circ}$, $0.98 \times 0.98 \mathrm{~mm}^{2}$ ) with 19 axial $5 \mathrm{~mm}$ slices and $1.2 \mathrm{~mm}$ gap of the whole head were used for clinical neurodiagnostic evaluation.

Processing was done on the neuroimaging computer network of the Department of Psychiatry, University Medical Center Utrecht. All images were coded to ensure blindness for subject identification and diagnoses, scans were manually put into Talairach frame (no scaling) for segmentation purposes and corrected for inhomogeneities in the magnetic field (Sled et al., 1998). Segments of gray and white matter of the cerebrum (total brain excluding cerebellum and stem) were based on histogram analyses (Schnack et al., 2001, 2009). All images were checked after measurement and corrected manually if necessary. The inter-rater reliabilities of the volume measurements, determined by the intraclass correlation coefficient (ICC), were 0.95 and higher.

For cortical thickness measurements, we used a custom implementation of the CLASP algorithm (Kim et al., 2005; Lyttelton et al., 2007) which starts from the gray and white matter segments created by our own algorithm. Cortical thickness extraction was done by hemisphere; each surface consisted of 40,960 polygons and 40,962 vertices. It included fitting of a 3D surface to the white matter/gray matter interface, which created the inner surface of the cortex which was then expanded out to fit the gray matter/cerebrospinal fluid interface, thereby creating the outer cortical surface (Kim et al., 2005). Cortical thickness was estimated by taking the distance between the two surfaces such that each polygon vertex on the outer surface had a counterpart vertex on the inner surface. A vertex-by-vertex analysis was carried out to evaluate the variability in cortical thickness change at each point. Each subject's thickness measurements were smoothed across the surface using a $20 \mathrm{~mm}$ full-width at half-maximum (FWHM) surface-based blurring kernel. This method of blurring improves the chances of detecting population differences but also follows the curvature of the surface to preserve any anatomical boundaries within the cortex. The surfaces of the subjects were registered to an average surface created from 152 subjects (International Consortium for Brain Mapping) (Lyttelton et al., 2007). This registration allowed us to compare cortical thickness locally between subjects. It should be noted that the area defined as the parahippocampal gyrus comprises parts of the entorhinal cortex, perirhinal cortex, parahippocampal cortex, and those parts of the uncus and hippocampus proper that are on the cortical surface in the medial temporal lobe (Lerch, 2008).

Cognitive assessment. A measure of full IQ (WAIS-III, 1997) was obtained in 132 subjects who had a baseline scan and for 106 participants who also obtained a follow-up scan. Full-scale IQ was corrected for age and sex.

Statistical analyses. To estimate the contribution of genetic and common and unique environmental factors on the variation of brain struc- ture change, the extended twin-sibling model was applied. This model is identified because monozygotic (MZ) twins are (nearly always) genetically identical, whereas dizygotic (DZ) twins and siblings share $50 \%$ of their segregating genes on average and both types of twins and their siblings share their familial environment. Therefore, if MZ twins resemble each other more than DZ twins for a particular trait, genetic factors are important for that trait. The presence of common environmental factors is suggested when correlations in DZ twins are larger than half the MZ correlation (Boomsma et al., 2002). By including siblings of twins, the statistical power to detect the influences of common environmental factors shared by family members is enhanced (for example, a family of $\mathrm{DZ}$ twins and a sib gives three correlations among first-degree relatives, a family with only two DZ twins gives one correlation).

For every vertex, cortical thickness as well as cortical thickness change were corrected for age, sex, and handedness with a linear regression analysis. The relative importance of the genetic factor was estimated on the age/sex/handedness corrected residuals, which was expressed as (univariate) heritability $\left(\mathrm{h}^{2}\right)$. Because univariate analysis did not show any evidence for influences of common environment (C), subsequent (bivariate) analyses were based on models containing additive genetic (A) and unique environmental (E) influences only. The covariance between brain volume and brain volume change and between brain volume change and IQ (bivariate genetic analysis), was decomposed into two parts and the percentage covariance attributed to A was expressed as bivariate heritability $\left(\mathrm{h}_{\text {biv }}^{2}=\left|\operatorname{cov}_{\mathrm{A}}\right| /\left(\left|\operatorname{cov}_{\mathrm{A}}\right|+\left|\operatorname{cov}_{\mathrm{E}}\right|\right)\right)$.

The bivariate genetic analysis yielded an estimate of the phenotypic correlations $\left(\mathrm{r}_{\mathrm{ph}}\right)$ between brain structure and brain structure change and between brain structure change and IQ, which can result from a shared set of genes or a shared set of environmental factors depicted in genetic $\left(r_{g}\right)$ and environmental correlations $\left(r_{e}\right)$. These estimates provide information regarding the possible shared genetic and environmental influences of brain structure and brain structure change and brain structure change and IQ. Decomposition of these sources was based on the comparison of cross-trait/cross-twin correlations for MZ and DZ twins (i.e., the correlation between a trait [e.g., whole brain volume at initial measurement] of twin 1 with another trait [e.g., whole brain volume change] of twin 2, where twin 1 and twin 2 represent a twin-pair). If the absolute value of the correlation between brain volume change of twin 1 and brain volume or IQ of twin 2 is larger in MZ twins than in DZ twins, this indicates that genes influencing brain volume (partly) overlap with genes that influence brain volume change. The extent of the overlap is reflected by the magnitude of the genetic correlation $\left(\mathrm{r}_{\mathrm{g}}\right)$.

We tested whether an AE model (family resemblance is solely attributable to additive genetic effects) fitted as well as an E model (no family resemblance), taking the simplest model explaining the data best (Neale, 2004). By minimizing a goodness-of-fit statistic between observed and predicted covariance matrices, likelihoods of nested models were compared ( $-2 \log$ likelihood difference is $\chi^{2}$ distributed). A $\chi^{2}$ larger than $\chi^{2}=3.84(1 \mathrm{df})$ or $5.99(2 \mathrm{df})$ indicates a significant difference at $\alpha=0.05$, which means that the reduced model provided a significantly worse fit to the data and indicates that the discarded effect (e.g., additive genetic influence) cannot be left out of the model without seriously deteriorating the goodness-of-fit. When estimating heritabilities, this $\chi^{2}$ can be relaxed because tests of variance components constrained to be nonnegative correspond to tests of parameters on the boundary of the parameter space and in such situations the standard test procedure provides too large $p$ values. These $p$ values have to be halved, resulting in a critical value of $\chi^{2}=2.71$ ( $1 \mathrm{df}$ ) at $\alpha=0.05$ (Dominicus et al., 2006). A critical $\chi^{2}$ larger than $\chi^{2}=14.3$ was set after Bonferroni correction for multiple comparisons based on 81,920 polygons and the $20 \mathrm{~mm}$ surfaced based blurring kernel.

\section{Results}

Change in cortical thickness was measured as thickening and thinning per vertex (corner of one triangle of cortical tissue of over 80,000 triangles that together form the cortex) over the 5 year interval and set against age for interpretation (Fig. 1). Cortical thickening was found bilaterally in the parahippocampal 


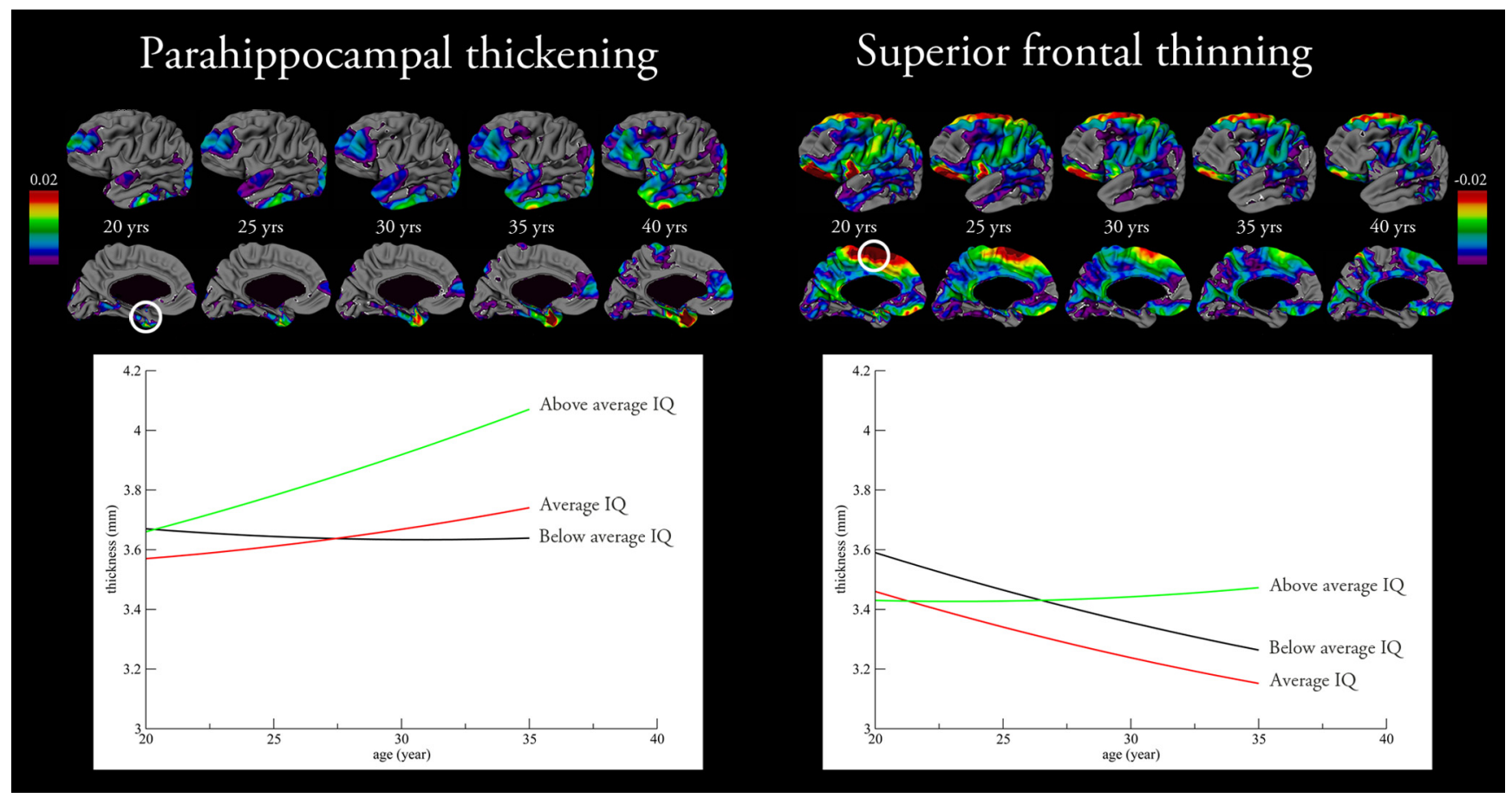

Figure 1. Cortical thickness change in the adult human brain and intelligence. The cortical maps show the mean cortical thickening (left) and thinning (right) in mm change with age between 20 and 40 years. The graphs show the cortical thickness change in the parahippocampal cortex and superior frontal cortex for the three intelligence groups. The maximum change in cortical thickness was $-0.026 \mathrm{~mm}$ per year.

Table 2. Cortical thickness change and intelligence: peak values of the $r_{p h}$ map between thickness change and IQ

\begin{tabular}{|c|c|c|c|c|c|c|c|}
\hline \multirow[b]{2}{*}{ Cortical area } & \multirow{2}{*}{$\begin{array}{l}\text { Coordinates } \\
X, Y, Z\end{array}$} & \multirow{2}{*}{$\begin{array}{l}\text { Cortical thickness change } \\
\mathrm{h}^{2}(\%)[\mathrm{Cl}]\end{array}$} & \multicolumn{5}{|c|}{ Cortical thickness change and intelligence } \\
\hline & & & $\mathrm{h}_{\text {biv }}^{2}(\%)[\mathrm{Cl}]$ & $\chi^{2} r_{p h}$ & $\mathrm{r}_{\mathrm{ph}}$ & $r_{g}$ & $\mathrm{r}_{\mathrm{e}}$ \\
\hline \multicolumn{8}{|l|}{ Thickening } \\
\hline Parahippocampal left & $-27,-7,-5$ & $22[9$ to 45$]$ & $71[58$ to 83$]$ & 20.89 & $0.26[0.09$ to 0.42$]$ & $1.00[0.49$ to 1.00$]$ & $-0.71[-0.86$ to -0.36$]$ \\
\hline Parahippocampal right & $24,-25,-27$ & $10[2$ to 29$]$ & 82 [62 to 100$]$ & 12.06 & $0.24[0.06$ to 0.40$]$ & $1.00[0.35$ to 1.00$]$ & $-0.27[-0.55$ to 0.09$]$ \\
\hline Medial frontal right & $3,39,28$ & $9\left[\begin{array}{l}1 \\
\text { to } 23]\end{array}\right]$ & $94[71$ to 100$]$ & 13.01 & $0.27[0.09$ to 0.43$]$ & $1.00[0.46$ to 1.00$]$ & $-0.07[-0.39$ to 0.29$]$ \\
\hline \multicolumn{8}{|l|}{ Thinning } \\
\hline Superior frontal left & $-4,24,60$ & $5[1$ to 32$]$ & $85[20$ to 100$]$ & 11.20 & $0.24[0.08$ to 0.39$]$ & $1.00[0.10$ to 1.00$]$ & $0.14[-0.26$ to 0.49$]$ \\
\hline Superior frontal right & $25,13,53$ & $27[4$ to 54$]$ & $92[73$ to 100$]$ & 16.89 & $0.32[0.15$ to 0.47$]$ & $0.70[0.33$ to 1.00$]$ & $-0.13[-0.54$ to 0.33$]$ \\
\hline Medial frontal left & $-9,36,10$ & $19[1$ to 44$]$ & $60[11$ to 78$]$ & 12.75 & $0.08[-0.12$ to 0.27$]$ & $0.56[0.03$ to 1.00$]$ & $-0.66[-0.84$ to -0.29$]$ \\
\hline Inferior frontal left & $-41,24,23$ & $9[1$ to 25$]$ & $88[48$ to 100$]$ & 14.42 & $0.33[0.14$ to 0.49$]$ & $1.00[0.39$ to 1.00$]$ & $0.18[-0.17$ to 0.49$]$ \\
\hline Inferior frontal right & $47,21,23$ & $13[1$ to 38$]$ & $82[31$ to 100$]$ & 14.44 & $0.34[0.14$ to 0.49$]$ & $0.81[0.19$ to 1.00$]$ & $0.25[-0.18$ to 0.58$]$ \\
\hline Sup. temporal/Heschl left & $-40,-19,-3$ & $14[1$ to 37$]$ & $76[47$ to 100$]$ & 9.31 & $0.20[-0.01$ to 39$]$ & $0.81[0.17$ to 1.00$]$ & $-0.38[-0.69$ to 0.12$]$ \\
\hline Med. parietal/precuneus left & $-10,-58,54$ & $22[4$ to 47$]$ & $94[73$ to 100$]$ & 14.00 & $0.35[0.15$ to 0.51$]$ & $0.83[0.32$ to 1.00$]$ & $-0.12[-0.55$ to 0.38$]$ \\
\hline Superior sensory left & $-29,-27,59$ & $17[5$ to 37$]$ & $82[64$ to 100$]$ & 15.70 & $0.31[0.12$ to 0.48$]$ & $1.00[0.50$ to 1.00$]$ & $-0.40[-0.68$ to 0.08$]$ \\
\hline Superior sensory right & $28,-36,69$ & 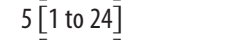 & $61[7$ to 93$]$ & 20.92 & $0.34[0.17$ to 0.50$]$ & $1.00[0.19$ to 1.00$]$ & $0.51[0.10$ to 0.74$]$ \\
\hline Occipital pole right & $28,-99,-9$ & $9[1$ to 22$]$ & $84[46$ to 100$]$ & 21.18 & $0.34[0.18$ to 0.48$]$ & $1.00[0.54$ to 1.00$]$ & $0.22[-0.19$ to 0.56$]$ \\
\hline
\end{tabular}

Confidence intervals crossing 0 are not significant for $r_{p h}, r_{g}, r_{e}$. Cortical thickness change was corrected for age and gender

$\mathrm{h}^{2}$ : sources of variance on cortical thickness change. This measure reflects the influence of additive genetic factors on cortical thickness change in percentages and $95 \%$ confidence interval (e.g., additive genetic effects account for $22 \%$ of the variance on change in the peak vertex of the parahippocampal gyrus in the left hemisphere).

$\mathrm{h}_{\text {biv }}^{2}$ : bivariate heritability, the influence of genetic factors on the correlation between cortical thickness change in this vertex and IQ. That is, additive genetic effects account for $71 \%$ of the covariance of cortical thickness change in the peak vertex of the parahippocampal gyrus in the left hemisphere and IQ.

Phenotypic correlation $\left(r_{\mathrm{p}}\right)$ : correlation that is found between cortical thickness change in this vertex and I 0 within individuals. For example, the correlation between cortical thickness change in the peak vertex of the left parahippocampal gyrus left and IQ $=0.26$, which indicates that there is a significant correlation between cortical thickness change and IQ

Genetic and environmental correlation: phenotypic correlations are decomposed into genetic $\left(r_{g}\right)$ and environmental components $\left(r_{e}\right)$, providing information on the possible shared genetic and environmental influences on cortical thickness change in this vertex and IQ. Note that in 8 of 13 cases, $r_{g}$ and $r_{\mathrm{e}}$ are of opposing sign. However, this is significant in only 2 of 13 cases. In all other cases the environmental correlation was not significantly different from 0.

gyri, bilaterally in the frontal poles, right medial frontal, and bilaterally in the occipital cortices. With increasing age, the cortical thickening in the parahippocampal gyrus became more prominent, whereas in the frontal poles and right medial frontal cortices it became less prominent. Cortical thinning with increasing age was primarily found in the superior, left medial, and inferior frontal, sensory-motor, insula, superior temporal, and lateral and medial parietal cortices.
Associations between cortical thickness change and level of intelligence were measured by phenotypic correlations. We divided our sample into three groups based on their IQ to interpret the differential changes in cortical thickness with age. Significant positive associations with level of intelligence were found for cortical thickening in the left and right parahippocampal cortices $\left(\mathrm{r}_{\mathrm{ph}}=0.26 ; \mathrm{r}_{\mathrm{ph}}=0.24\right)$ and right medial frontal $\left(\mathrm{r}_{\mathrm{ph}}=0.27\right)$ cortex, and for cortical thinning negative associations with level 
of intelligence were found in the left and right inferior frontal (near Broca's area; $\mathrm{r}_{\mathrm{ph}}=0.33$ and $\mathrm{r}_{\mathrm{ph}}=0.34$ ), left and right superior frontal $\left(r_{p h}=0.24 ; r_{p h}=0.32\right)$, left and right sensory-motor $\left(\mathrm{r}_{\mathrm{ph}}=0.31\right.$; $\left.\mathrm{r}_{\mathrm{ph}}=0.34\right)$, and right occipital $\left(\mathrm{r}_{\mathrm{ph}}=\right.$ 0.34 ) cortices (Fig. 1; Table 2; Figures S1 and S2, available at www.jneurosci.org as supplemental material). All associations indicate that increased thickening and less thinning of the cortex is associated with higher IQ scores.

Heritability of IQ in this sample was estimated to be $86 \%$ (95\% confidence interval $[\mathrm{CI}] 75$ to 92 ). Heritability for change in cortical thickness over time was determined to be up to $56 \%$. Cortical thickening was significantly heritable in the parahippocampal gyri (heritability given in percentages with $95 \% \mathrm{CI}$ ): left $48 \%, 25$ to $66 \%$; right $47 \%, 24$ to $64 \%$ ), frontal poles (left 45\%, 19 to 65\%; right $43 \%, 18$ to $63 \%)$ and right medial frontal cortex $(56 \%, 31$ to $73 \%)$ after Bonferroni correction for multiple comparisons (Fig. 2 ; Table 3). Cortical thinning was significantly heritable in the left orbitofrontal (41\%, 15 to $63 \%)$, superior temporal (left $55 \%, 32$ to $72 \%$; right $45 \%, 24$ to $62 \%$ ), left superior frontal ( $54 \%, 30$ to $72 \%)$, lateral parietal (left 28\%, 11 to $45 \%$; right $45 \%, 23$ to $63 \%)$, and right lateral $(38 \%$, 16 to $58 \%)$ and right medial $(35 \%, 6$ to $62 \%)$ occipital cortices after Bonferroni correction for multiple comparisons. Genetic factors influencing cortical thinning of the left superior frontal and superior temporal cortices were significantly different from those influencing absolute cortical thickness, and these findings remained significant after Bonferroni correction. This latter finding suggests that different genetic factors influence changes in cortical thickness and absolute cortical thickness in these areas. The influence of genes on cortical thickening in the parahippocampal gyrus changed over time. This was suggested by environmental influences on absolute parahippocampal thickness, whereas genetic factors were found to influence the changes in thickness. In the parietal and occipital cortices, the magnitude of changes was influenced by the same genes that affect absolute cortical thickness in these areas.

There were significant influences of shared genes on the associations between cortical thickness change and level of intelligence in the parahippocampal, medial frontal, inferior frontal, superior frontal, sensory-motor, and occipital cortices (Table 2). Thus, genes that are implicated in the changes in cortical thickness overlap with those involved in the level of intelligence.

\section{Discussion}

Here we report several novel findings: the brain changes throughout adulthood, these changes are related to intelligence, and both are partly driven by shared genes. Specifically, in this extended twin study we found the change in cortical thickness in the adult brain to be in the order of 0.5 to $1.0 \%$ per year, with thinning of the cortex most evident in the frontal areas while thickening of the $\mathbf{h}^{2}$ cortical thickness change

Different genetic influence
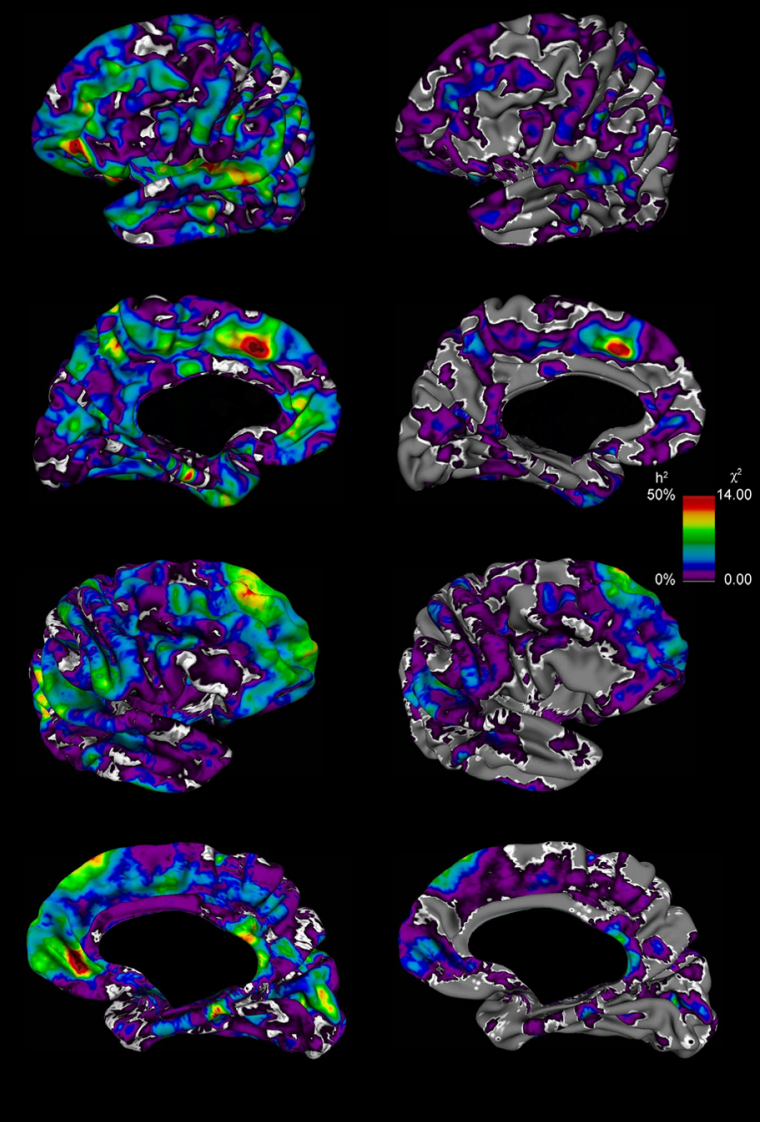

Figure 2. Heritability of cortical thickness and cortical thickness change showing the heritability ( $\mathrm{h}^{2}$ ) of cortical thickness (left) the heritability of cortical thickness change (middle), and the $\chi^{2}$ test statistics $\left(\chi^{2}, \mathrm{df}=1\right)$ of specific genetic influences on cortical thickness change, which are not associated with the genetic influences of absolute cortical thickness (right).

cortex was most pronounced in the medial temporal lobe. Interestingly, these changes were associated with the level of intelligence of the subjects: subjects with an IQ of over 110 showed both more pronounced thickening of the medial temporal cortex and attenuated thinning of the frontal cortex over time when compared to individuals with average (IQ 90 to 110) and below average intellectual ability $(<90)$. Although these data only extend to age 35, our findings suggest that the association between intellectual ability and cortical development as reported earlier in a large group of children (Shaw et al., 2006) does not stop after childhood and adolescence. In addition, we found the associations between intelligence and changes in cortical thickness to be heritable. Indeed, the heritability estimates that we found for changes in the brain over time are considerable. The highest values (between 50 and 56\%) were found in the frontal and temporal cortices including the parahippocampal gyri. The magnitude of several of these changes, and particularly of the thinning in the left superior frontal and left superior temporal cortices, was found to be partly influenced by genes that are different from those related to absolute cortical thickness in some of these areas. It may be possible that the genetic influence on cortical change is related to plastic properties of the brain needed for optimal adaptation to an ever-changing environment.

With increasing age, cortical thinning was more pronounced in our sample than cortical thickening, which is in agreement with volume decreases in overall gray matter over time in adults 
Table 3. Estimated influences of additive genetic $\left(\mathrm{h}^{2}\right)$ factors on cortical thickness and cortical thickness change and correlations between them

\begin{tabular}{|c|c|c|c|c|c|c|c|c|c|}
\hline \multirow[b]{2}{*}{ Cortical area } & \multirow[b]{2}{*}{$X, Y, Z$} & \multirow{2}{*}{$\begin{array}{l}\text { Cortical thickness } \\
\mathrm{h}^{2}(\%)[\mathrm{Cl}]\end{array}$} & \multicolumn{2}{|c|}{ Cortical thickness change } & \multicolumn{5}{|c|}{ Cortical thickness and cortical thickness change } \\
\hline & & & $\mathrm{h}^{2}(\%)[\mathrm{Cl}]$ & $\mathrm{h}^{2}\left(\chi^{2}\right)$ & $\mathrm{h}_{\text {biv }}^{2}$ & $A-\operatorname{spec}\left(\chi^{2}\right)$ & $r_{p h}$ & $r_{g}$ & $\mathrm{r}_{\mathrm{e}}$ \\
\hline \multicolumn{10}{|l|}{ Thickening } \\
\hline Medial frontal right & $3,36,-16$ & $16[0$ to 37$]$ & $56[31$ to 73$]$ & 17.09 & $35[0$ to 69$]$ & 1.45 & $-0.45[-0.56$ to -0.32$]$ & $-0.53[-1$ to 1$]$ & $-0.48[-0.66$ to -0.26$]$ \\
\hline Parahippocampal left & $-19,-20,-25$ & $7[0$ to 30$]$ & $48[25$ to 66$]$ & 19.85 & $7[0$ to 45$]$ & 0.35 & $-0.45[-0.56$ to -0.33$]$ & $-0.17[-1$ to 1$]$ & $-0.61[-0.75$ to -0.40$]$ \\
\hline Parahippocampal right & $15,-35,-10$ & $47[25$ to 64$]$ & $47[24$ to 64$]$ & 17.12 & $68[34$ to 97$]$ & 3.43 & $-0.49[-0.59$ to -0.37$]$ & $-0.71[-1$ to -0.38$]$ & $-0.29[-0.52$ to -0.02$]$ \\
\hline Sup. frontal left & $-4,25,38$ & 58 [37 to 73$]$ & 54 [30 to 72$]$ & 16.99 & $62[13$ to 95$]$ & $14.33^{*}$ & $-0.39[-0.52$ to -0.25$]$ & $-0.44[-0.71$ to -0.08$]$ & $-0.34[-0.57$ to -0.05$]$ \\
\hline Sup. temporal/Heschl's left & $-52,-13,7$ & $49[30$ to 64$]$ & $55[32$ to 72$]$ & 18.37 & $57[4$ to 94$]$ & $15.53^{*}$ & $-0.33[-0.46$ to -0.19$]$ & $-0.36[-0.65$ to -0.02$]$ & $-0.29[-0.51$ to -0.04$]$ \\
\hline Sup. temporal right & $55,-43,12$ & $50[31$ to 64$]$ & $45[24$ to 62$]$ & 17.43 & $54[16$ to 85$]$ & 11.15 & $-0.41[-0.52$ to -0.27$]$ & $-0.47[-0.75$ to -0.13$]$ & $-0.35[-0.55$ to -0.11$]$ \\
\hline Parietal, lateral left & $-42,-26,20$ & $45[27$ to 61$]$ & $28[11$ to 45$]$ & 19.00 & $74[43$ to 100$]$ & 0.00 & $-0.48[-0.58$ to -0.36$]$ & $-1[-1$ to -0.78$]$ & $-0.20[-0.39$ to 0.01$]$ \\
\hline Parietal lateral right & $59,-52,35$ & $13[0$ to 35$]$ & $45[23$ to 63$]$ & 15.02 & $27[0$ to 66$]$ & 0.94 & $-0.42[-0.53$ to -0.29$]$ & $-0.48[-1$ to 1$]$ & $-0.43[-0.62$ to -0.21$]$ \\
\hline Lat. occipital right & $44,-74,23$ & $15[2$ to 36$]$ & $38[16$ to 58$]$ & 20.81 & $27[0$ to 38$]$ & 0.11 & $-0.32[-0.44$ to -0.17$]$ & $0.76[-0.03$ to 1$]$ & $-0.68[-0.80$ to -0.50$]$ \\
\hline
\end{tabular}

Cortical areas with significant heritability for thickness change over time at $\alpha=0.05$ after Bonferroni correction for multiple comparisons $\left(\chi^{2}>14.3\right)$, corrected for age and gender. Confidence intervals crossing 0 are not significant for ${ }_{\text {ph }}$, $r_{g}, r_{e}$. Confidence intervals including -1 or 1 indicate that there is no evidence different genes are involved in cortical thickness change as compared to cortical thickness in that specific vertex.

$\mathrm{h}_{\text {biv }}^{2}$ : bivariate heritability; the influence of genetic factors on the correlation between cortical thickness and cortical thickness change. That is, additive genetic effects account for $6 \%$ of the covariance of cortical thickness and cortical thickness change in the peak vertex of the left frontal pole.

A-spec: specific genetic influence on cortical thickness change compared with cortical thickness; ${ }^{*}$ Significant at $\alpha=0.05$ with Bonferroni correction $\left(\chi^{2}>14.3\right)$.

Phenotypic correlation $\left(r_{\text {ph }}\right)$ : correlation that is found between cortical thickness and cortical thickness change within individuals. That is, the correlation between cortical thickness and cortical thickness change in the peak vertex of the left frontal pole $=-0.45$, which indicates that there is a significant correlation between cortical thickness and cortical thickness change.

Genetic and environmental correlation: phenotypic correlations are decomposed into genetic $\left(r_{g}\right)$ and environmental components $\left(r_{e}\right)$, providing information on the possible shared genetic and environmental influences on brain volume and brain volume change.

(Raz et al., 2005; Resnick et al., 2003; Kramer et al., 2007). The finding of cortical thickening in the frontal pole, right temporal, parahippocampal, and occipital cortex is consistent with a study in 20- to 77-year-olds, finding minimal change in the entorhinal cortex (part of the parahippocampus) and none in the primary visual cortex despite overall widespread loss of brain volume (Raz et al., 2005). Although at this point the physiological processes underlying cortical thickness change in the adult human brain remain unclear, it is interesting to note that the areas that showed cortical thickening in our study (i.e., the parahippocampal gyrus and frontal pole) overlap with those that are thought to have plastic properties in adult mammals (Gould, 2007). Cortical thinning with increasing age is not easily explained by decreases in neocortical neuronal cell number (Pakkenberg and Gundersen, 1997) but instead may result from a reduction in the complexity of dendrite arborization and dendritic length, a decrease in spine numbers, and change in synaptic densities (Dickstein et al., 2007).

Our finding that intelligence and change in cortical thickness are partly associated through shared genes is consistent with the dependence of learning and memory formation on the plasticity of neural circuits (Escobar et al., 2008). The association between intelligence and structural brain changes may also reflect an association between intelligence and plasticity in structural (Chiang et al., 2009) and functional brain networks during the resting-state (van den Heuvel et al., 2009). Moreover, because functional brain activity during cognitive tasks was recently found to be heritable (Koten et al., 2009), genes for structural brain plasticity and intellectual ability may also be relevant for brain function while performing cognitive tasks. Finally, the genetic association between intelligence and change in cortical thickness may assist in the quest to find the cause(s) for psychiatric disorders that affect both intellectual ability and brain plasticity. For instance, schizophrenia is characterized by compromised intellectual ability and progressive brain tissue loss (Brans et al., 2008), both of which are heritable traits implicated in the disease (Toulopoulou et al., 2007). In sum, we report here that not only does the brain continue to change well into adult- hood, these changes are functionally relevant because they are related to intelligence. The relevance of this association is underscored by our finding that brain changes and intelligence are both partly influenced by the same genes.

\section{References}

Andreasen NC, Flaum M, Arndt S (1992) The Comprehensive Assessment of Symptoms and History (CASH): an instrument for assessing diagnosis and psychopathology. Arch Gen Psychiatry 49:615-623.

Baaré WFC, Hulshoff Pol HE, Boomsma DI, Posthuma D, de Geus EJ, Schnack HG, van Haren NEM, van Oel CJ, Kahn RS (2001) Quantative genetic modeling of variation in human brain morphology. Cereb Cortex $11: 816-824$.

Boomsma DI (2010) Netherlands twin register. Amsterdam: Vrije Universiteit. Available at www.tweelingenregister.org/index_uk.html.

Boomsma DI, Busjahn A, Peltonen L (2002) Classical twin studies and beyond. Nat Rev Genet 3:872-882.

Brans RGH, van Haren NEM, van Baal GCM, Schnack HG, Kahn RS, Hulshoff Pol HE (2008) Heritability of changes in brain volume over time in twin pairs discordant for schizophrenia. Arch Gen Psychiatry 65:1259-1268

Chiang MC, Barysheva M, Shattuck DW, Lee AD, Madsen SK, Avedissian C, Klunder AD, Toga AW, McMahon KL, de Zubicaray GI, Wright MJ, Srivastava A, Balov N, Thompson PM (2009) Genetics of brain fiber architecture and intellectual performance. J Neurosci 29:2212-2224.

Dickstein DL, Kabaso D, Rocher AB, Luebke JI, Wearne SL, Hof PR (2007) Changes in the structural complexity of the aged brain. Aging Cell 6:275-284

Dominicus A, Skrondal A, Gjessing HK, Pedersen NL, Palmgren J (2006) Likelihood ratio tests in behavioral genetics: problems and solutions. Behav Genet 26:331-340.

Escobar G, Fares T, Stepanyants A (2008) Structural plasticity of circuits in cortical neuropil. J Neurosci 28:8477-8488.

Giedd JN, Blumenthal J, Jeffries NO, Castellanos FX, Liu H, Zijderbosch A, Paus T, Evans AC, Rapoport JL (1999) Brain development during childhood and adolescence: a longitudinal MRI study. Nat Neurosci 2:861-863.

Gogtay N, Giedd JN, Lusk L, Hayashi KM, Greenstein D, Vailtuzis AC, Nugent TF 3rd, Herman DH, Clasen LS, Toga AW, Rapoport JL, Thompson PM (2004) Dynamic mapping of human cortical development during childhood through early adulthood. Proc Natl Acad Sci U S A 25:8174.

Gould E (2007) How widespread is adult neurogenesis in mammals? Nat Rev Neurosci 8:481-488. 
Hulshoff Pol HE, Kahn RS (2008) What happens after the first episode? A review of progressive brain changes in chronically ill patients with schizophrenia. Schizophr Bull 34:354-366.

Kim JS, Singh V, Lee JK, Lerch J, Ad-Dab'bagh Y, MacDonald D, Lee JM, Kim SI, Evans AC (2005) Automated 3-D extraction and evaluation of the inner and outer cortical surface using a Laplacian and partial volume effect classification. Neuroimage 27:210-221.

Koten JW Jr, Wood G, Hagoort P, Goebel R, Propping P, Willmes K, Boomsma DI (2009) Genetic contribution to variation in cognitive function: an fMRI study in twins. Science 323:1737-1740.

Kramer JH, Mungas D, Reed BR, Wetzel ME, Burnett MM, Miller BL, Weiner MW, Chui HC (2007) Longitudinal MRI and cognitive change in healthy elderly. Neuropsychology 21:412-418.

Lerch JP (2008) Automated cortical thickness measurements from MRI can accurately separate Alzheimer's patients from normal elderly controls. Neurobiol Aging 29:23-30.

Liu RS, Lemieux L, Bell GS, Sisodiya SM, Shorvon SD, Sander JW, Duncan JS (2003) A longitudinal study of brain morphometrics using quantitative magnetic resonance imaging and difference image analysis. Neuroimage 20:22-33.

Lyttelton O, Boucher M, Robbins S, Evans A (2007) An unbiased iterative group registration template for cortical surface analysis. Neuroimage 34:1535-1544.

Maxwell ME (1992) Manual for the FIGS (Family Interview for Genetic Studies). Bethesda, MD: Clinical Neurogenetics Branch, Intramural research Program, National Institute of Mental Health.

Neale MC (2004) Mx documentation. Richmond, VA: Virginia Commonwealth University. Available at http://www.vcu.edu/mx/documentation.html.

Pakkenberg B, Gundersen HJ (1997) Neocortical neuron number in humans: effect of sex and age. Comp Neurol 384:312-320.

Plomin R, Spinath FM (2004) Intelligence, genetics, genes and genomics. J Pers Soc Psychol 86:112-129.

Posthuma D, de Geus EJ, Baaré WFC, Hulshoff Pol HE, Kahn RS, Boomsma DI (2002) The association between brain volume and intelligence is of genetic origin. Nat Neurosci 5:83-84.

Ramõn y Cajal S (1892) El nuevo concepto de la histologia de los centros nerviosos. Rev Ciencias Méd Barcelona 18:361-376, 457-476, 505-520, $529-541$
Raz N, Lindenberg U, Rodrigue KM, Kennedy KM, Head D, Williamson A Dahle C, Gerstorf D, Acker JD (2005) Regional brain changes in aging healthy adults: general trends, individual differences and modifiers. Cereb Cortex 145:1676-1689.

Resnick SM, Pham DL, Kraut MA, Zonderman AB, Davatzikos C (2003) Longitudinal magnetic resonance imaging studies of older adults: a shrinking brain. J Neurosci 23:3295-3301.

Schnack HG (2009) Techniques description: processing pipeline, a short overview. Utrecht, The Netherlands: Neuroimaging Research Group, Department of Psychiatry, University Medical Centre Utrecht. Available at www.neuromri.nl/ supplementary/techniques_description_v1.html.

Schnack HG, Hulshoff Pol HE, Baaré WFC, Staal WG, Viergever MA, Kahn RS (2001) Automated separation of gray and white matter from MR images of the human brain. Neuroimage 13:230-237.

Shaw P, Greenstein D, Lerch J, Clasen L, Lenroot R, Gogtay N, Evans A, Rapoport J, Giedd J (2006) Intellectual ability and cortical development in children and adolescents. Nature 440:676-679.

Sled JG, Zijdenbosch AP, Evans AC (1998) A nonparametric method for automatic correction of intensity nonuniformity in MRI data. IEEE Trans Med Imaging 17:87-97.

Thompson PM, Cannon TD, Narr KL, van Erp T, Poutanen VP, Huttunen M, Lönnqvist J, Standertskjöld-Nordenstam CG, Kaprio J, Khaledy M, Dail R, Zoumalen CI, Toga AW (2001) Genetic influences on brain structure. Nat Neurosci 12:1253-1258.

Toga AW, Thompson PM (2005) Genetics of brain structure and intelligence. Annu Rev Neurosci 28:1-23.

Toulopoulou T, Picchioni M, Rijsdijk F, Hua-Hall M, Ettinger U, Sham P, Murray R (2007) Substantial genetic overlap between neurocognition and schizophrenia. Arch Gen Psychiatry 64:1348-1355.

van den Heuvel MP, Stam CJ, Kahn RS, Hulshoff Pol HE (2009) Efficiency of functional brain networks and intellectual performance. J Neurosci 29:7619-7624.

Van Leeuwen M, Peper JS, van den Berg SM, Brouwer RM, Hulshoff Pol HE, Kahn RS, Boomsma DI (2009) A genetic analysis of brain volume and IQ in children. Intelligence 37:181-191.

Wechsler D (1997) Wechsler adult intelligence scale, Ed 3 (Dutch version), Lisse: Swets and Zeitlinger. 